RECEIVED

NOV 171995

Q.8TI

\title{
Mega-Joule Experiment Area Study, 1989
}

\author{
D. Slaughter \\ C. Oirth \\ J. Woodworth
}

This paper was prepared for a

Statement of Work

March 9, 1995

This is an informal report intended primarily for internal or limited external distribution. The opinions and conclusions stated are those of the author and may or may not be those of the Laboratory.

Work performed under the auspices of the U.S. Department of Energy by the Lawrence Livermore National Laboratory under Contract W-7405-Eng-48. 


\section{DISCLAIMER}

This document was prepared as an account of work sponsored by an agency of the United States Government. Neither the United States Government nor the University of Califomia nor any of their employees, makes any warranty, express or implied, or assumes any legal liability or responsibility for the accuracy, completeness, or usefulness of any information, apparatus, product, or process disclosed, or represents that its use would not infringe privately owned rights. Reference herein to any specific commercial product, process, or service by trade name, trademark, manufacturer, or otherwise, does not necessarily constitute or imply its endorsement, recommendation, or favoring by the United States Government or the University of California. The views and opinions of authors expressed herein do

$\because \cdots$ not necessarily state or reflect those of the United States Government or the University of California, and shall not be used for advertising or product endorsement purposes.

This report has been reproduced directly from the best available copy.

Available to DOE and DOE contractors from the Office of Scientific and Technical Information

P.O. Box 62, Oak Ridge, TN 37831

Prices available from (615) 576-8401, FTS 626-8401

Available to the public from the

National Technical Information Service

U.S. Department of Commerce

5285 Port Royal Rd.,

Springfield, VA 22161 


\section{Water frost first wall}

An earlier section of the present chapter has presented a summary of the important interactions of intense ICF $x$-ray emissions with the first wall of a containment chamber at small radii of the order of $R=5 \mathrm{~m}$. It is clear that the surface of any material at this distance will be vaporized to a depth of $10-100 \mu \mathrm{m}$. This was shown in section A4. Appendix $\mathrm{H}-1$ shows that shocks generated by $\mathrm{x}$-ray induced ablation of the aluminum surface at the first wall are attenuated sufficiently so that spallation is avoided even for full yield shots so long as the first wall is several $\mathrm{cm}$ thick. However, the computer simulations and experiments did not address the material changes which may accompany repeated exposure to full yield irradiation. Experimental simulations reached, at most, four exposures at fluences of $100 \mathrm{~J} / \mathrm{cm}^{2}$. The effect of repeated exposure where large compressions are produced near the exposed surface due to very high compressive stresses may be to work harden the material, or otherwise change its strength and shock propagation properties. For this reason, as well as the uncertainties in the simulation, and the desire for a high level of reliability, a design safety margin is desired and none is provided if the aluminum wall is only $3-5 \mathrm{~cm}$ thick. Therefore, a sacrificial innerlayer is added to the wall in order to substantially reduce the shock pressure in the aluminum and add a corresponding shock performance safety margin to the design.

In addition to the risk of shock induced spallation or other failure, erosion of the aluminum surface and consequent deposition of aluminum on other surfaces including diagnostics and final optics is to be avoided. The sacrificial frost layer serves this purpose well, replacing aluminum with water vapor as the ablated material. Coating the wall with a sacrificial layer of low density water frost which will be largely vaporized will 33: 1) substantially attenuate the shock reaching the 
surface of the permanent wall, 2) produce blow-off material which will not damage the optics or diagnostic instruments, and 3) aid in reducing the accumulation of neutron activated target debris on the wall. In addition, the cryogenic first wall which is required for frost wall protection reduces the thermal radiation loading of cryogenic ICF targets very substantially, as discussed in Chapter 4.

Emissions from a full yield target will vaporize approximately $8 \mathrm{~kg}$ of the frost layer. After the vaporized material expands away from the wall, it cools by converting its thermal energy into kinetic energy as it fills the target chamber. Upon reaching the center of the chamber, it rethermalizes by converting its kinetic energy back into thermal energy, radiating to the wall, and expanding outward. After many reverberations, the vapor reaches thermal equilibrium at $1 / 3$, having cooled primarily by vaporizing and dissociating more frost. Since the thermal conductivity of frost is poor, there may be as much as ten times more water vaporized during this process. After a much longer period of time, limited by thermal conductivity at the wall, the water and other vaporized debris will condense on the wall surface, as well as other surfaces such as optics and diagnostics. As long as a residual frost layer remains as condensation is taking place, the radioactive materials including tritium and activated debris will be deposited within the frost layer, and may be removed by warming the wall and draining the resulting water from the chamber. Figure C3-1 shows the structure and dimensions of the first wall in cross section.

\section{Figure C3-1 Cross section of water frost first wall.}

The frost layer has a density of roughly $0.1 \mathrm{gm} / \mathrm{cm}^{3}$ and thickness of roughly 2 $\mathrm{cm}$ for adequate shock protection and sufficient safety margin for non-uniform coverage to accommodate a full yield shot. The total mass is approximately $630 \mathrm{~kg}$. Calculations using the code PROFILE 34 indicate that a $1400 \mathrm{MJ}$ target yield will vaporize and partially dissociate about $8 \mathrm{~kg}$ (to a depth of $260 \mu \mathrm{m}$ ) of frost on a time scale of nanoseconds, assuming $500 \mathrm{MJ}$ in $x$-rays and debris. At most $160 \mathrm{~kg}$ of frost could be vaporized (to a depth of $5 \mathrm{~mm}$ ) if dissociation and thermal conduction are ignored 33 .

\section{a) Computer modeling of frost ablation and shock propagation}

DYNA2D 35 computer code calculations have been made to ascertain the probability of rear surface spall for an aluminum substrate. Results indicate that a $1000 \mathrm{MJ}$ shot, which will illuminate the first wall with an $x$-ray fluence on the order of $100 \mathrm{~J} / \mathrm{cm}^{2}$, creates a shock stress in the frost that is orders of magnitude lower than that created in either full density ice or bare aluminum. The porosity of the frost reduces the maximum tension in the substrate to only about 10 bars, which is about a factor of 100 less than the anticipated damage threshold. Similar results are indicated for other substrates such as fiber reinforced polymer. 
During post shot vapor condensation, which lasts at least tens of milliseconds, the residual frost or liquid water on the wall will not move more than several millimeters under the action of gravity. We assume that condensates will form directly on this frost/water, and not on the substrate. These condensates will include any activated target debris.

Calculations of $x$-ray induced ablation and shock propagation in low density frost have been carried out 46 and compared with experimental data obtained with snow 47 . Frost was assumed to have density of cither 0.1 or $0.3 \mathrm{gm} / \mathrm{cm}^{3}$, and an energy deposition profile as shown in Figure C3-2 below.

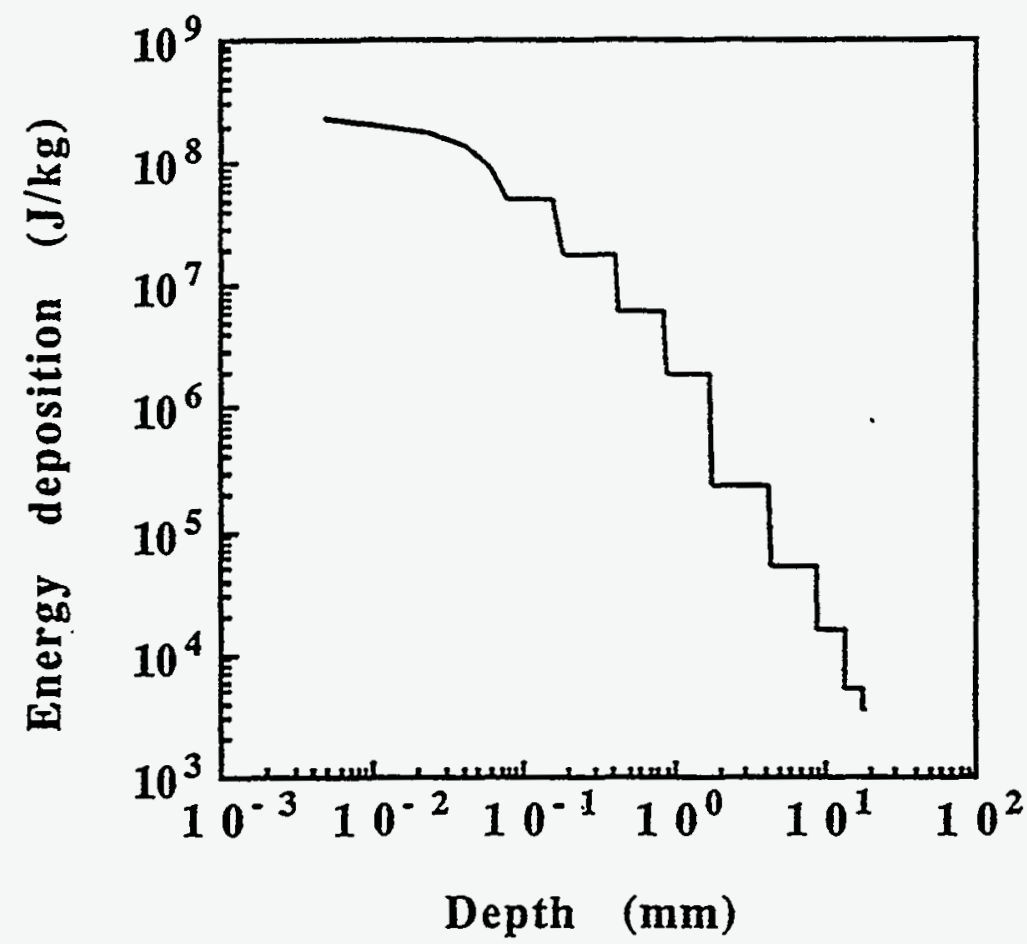

Figure C3-2 Energy deposition profile assumed in computer simulations.

The profile indicated is characteristic of $100 \mathrm{~J} / \mathrm{cm}^{2}$ of x-rays at mean energy about 1 $\mathrm{keV}$. Energy deposition was assumed instantaneous. An equation of state was developed using Hugoniot of water in its solid phase, but with reduced density and minor modifications introduced in order to properly simulate experimental data obtained in snow 47 . The pore crush model due to Butkovich 105 was included to better represent shock propagation in porous media such as snow and frost. Shock pressure, density, material velocity, and momentum were calculated as a function of time as the ablation generated shock propagated through the frost and into the aluminum substrate. Frost layers of $6.7,10$, and $20 \mathrm{~mm}$ thickness were investigated. Figure C3-3 below shows the envelope of peak shock pressure in these materials. 


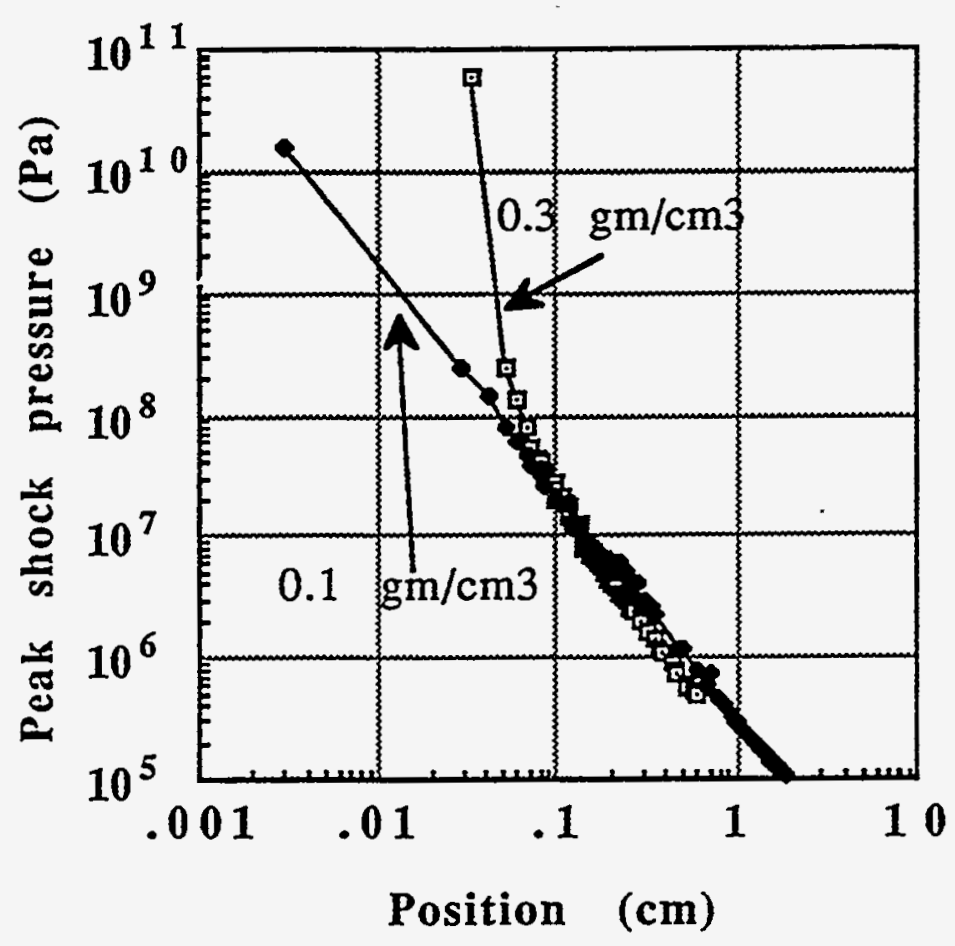

Figure C3-3 Peak shock pressure in frost at 0.1 and 0.3 density.

At the far right of the figure the shock enters an aluminum substrate and propagates with some additional attenuation. The noteworthy feature of the figure is the dramatic attenuation of peak pressure. At the point where the shock enters the aluminum substrate the pressures are predicted to be on the order of $10 \mathrm{bar}$, whereas the pressure at the exposed surface was on the order of $100 \mathrm{kbar}$. Clearly, the coupling of the shock wave into the aluminum is too small to result in spall even in a thin substrate material. These results indicate that an aluminum structural wall, the frost substrate, is adequately protected by the frost so that erosion and significant shock generation in the aluminum is prevented even if the first wall is placed at radii as small as $R=2 \mathrm{~m}$.

Calculated shock pressures were also integrated in time to predict the impulse delivered to the aluminum substrate. Figure C3-4 shows the results. 


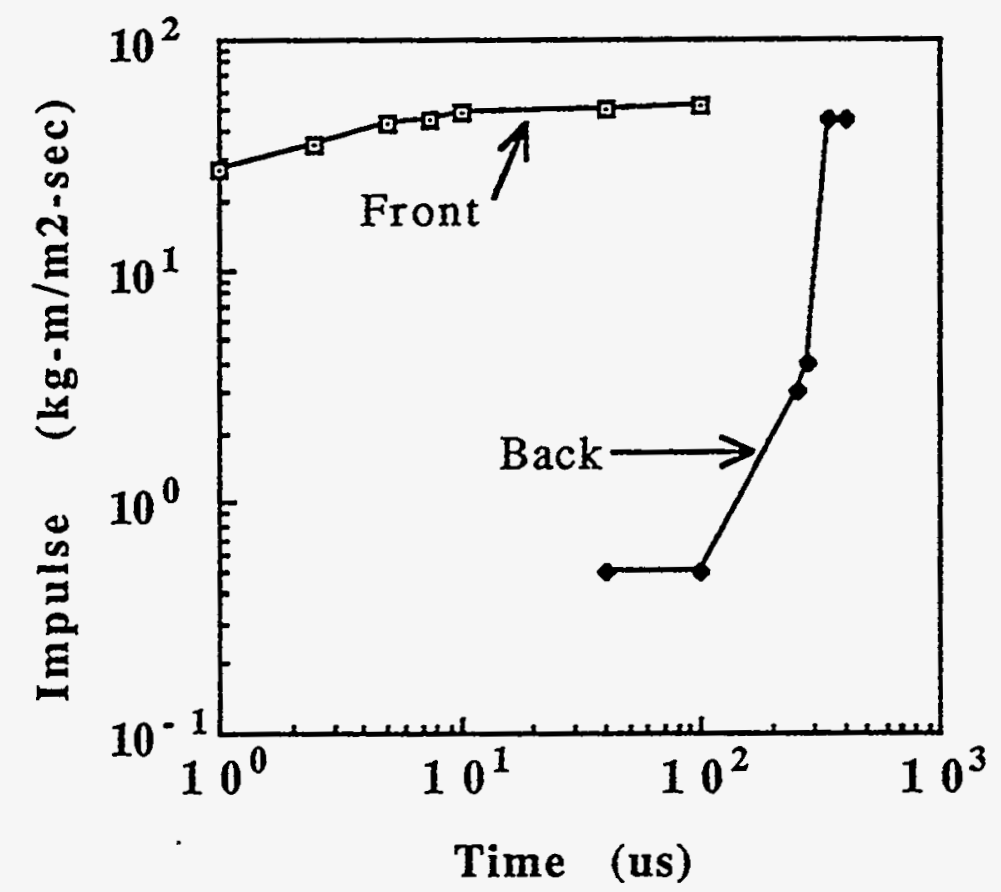

Figure C3-4 Impulse as a function of time at frost-aluminum interface.

Note that the impulse imparted to the substrate is delivered over several $\mu \mathrm{s}$. The impulse calculated in this manner is in relatively good agreement with the simple models presented in section A above. These values are later used to determine the wall thickness and strength required for the target chamber first wall.

\section{b) Experimental characterization of water frost}

\section{1) Frost crystal morphology}

Experimental characterization of frost and development of controlled growth techniques have been carried out during the past year 36 . This program was initiated to determine the frost growth rate, thermal conductivity, crush strength, the ability to withstand shock and vibration, and to verify its performance when illuminated by non-penetrating radiation at very high fluences.

When grown from the vapor phase, frost crystais exist in a variety of forms. The type of crystal growth depends on both the temperature of the surface and the amount of supersaturation (excess vapor density) present37. Frost experiments were performed in a vacuum chamber at a vapor pressure of about 5 torr. The excess vapor density of the experiments is shown in Figure C3-5 


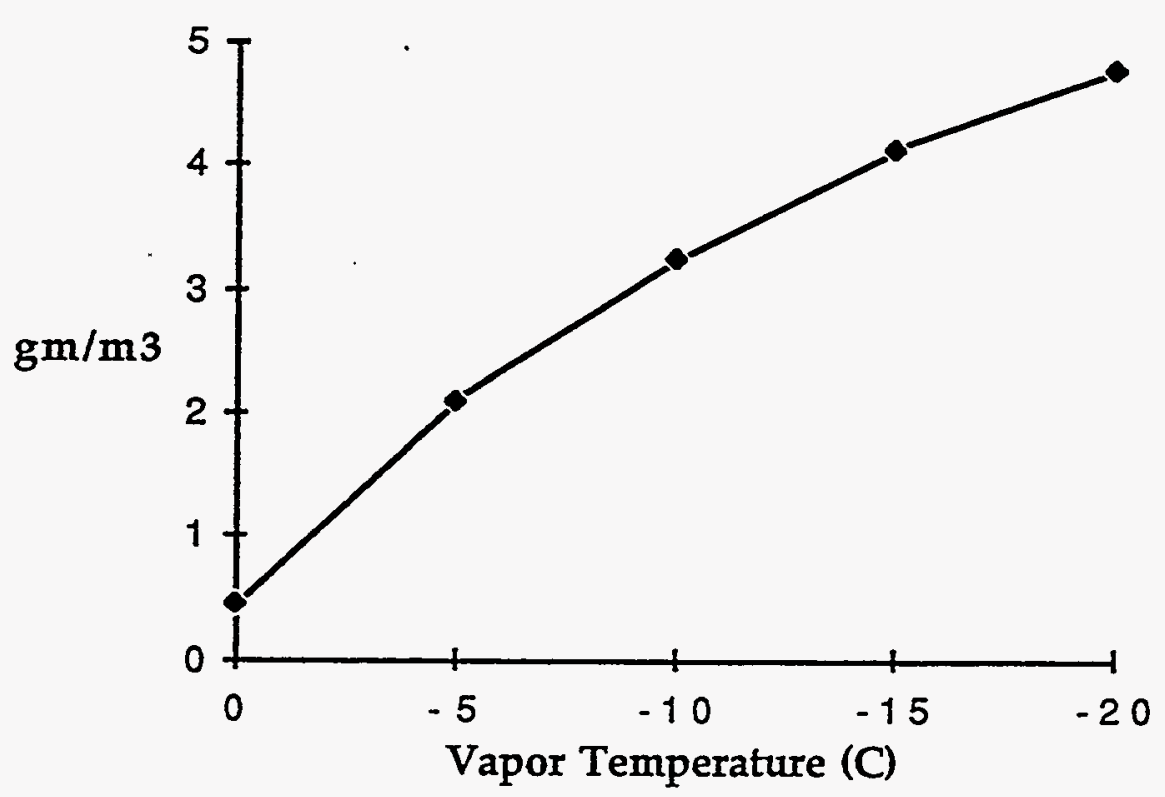

Figure C3-5 Excess vapor density in frost experiments.

At temperatures other than the triple point, the vapor pressure of the liquid and solid are different. Their difference at any temperature is the amount of supersaturation available at that temperature and is plotted in Figure C3-6

Figure C3-6 Growth forms of frost crystals (ETEC fig 1).

The temperature of the water bath in the experiments was higher than the temperature of the frost surface, causing excess densities well above this saturation curve. Three separate regions of growth occur. At high temperatures (near the melting point), solidification from a liquid boundary occurs. Growth rates for this type of growth have been modeled. At low temperature, frost growth occurs by adhesion to nucleation sites. The basic form of ice crystals, either plate or column, depends on the ratio of growth rates of basal (0001) and prism (1010) faces. The . change in basic form with temperature occurs with each crossover of the 0001 and 1010 curves. A ratio greater than one leads to column crystals, while a ratio less than one leads to plate type crystals. The range of temperature and vacuum conditions during the experiments allowed observation of several types of crystals including plate, needle, sheath, sector, and dendrite growth.

Experiments showed that the frost morphology is very dependent on ambient gas pressure. When the belljar described in the next section was opened to atmospheric pressure, the frost morphology changed within one second, as verified by TV pictures taken through a microtelescope.

\section{2) Experiment configuration}




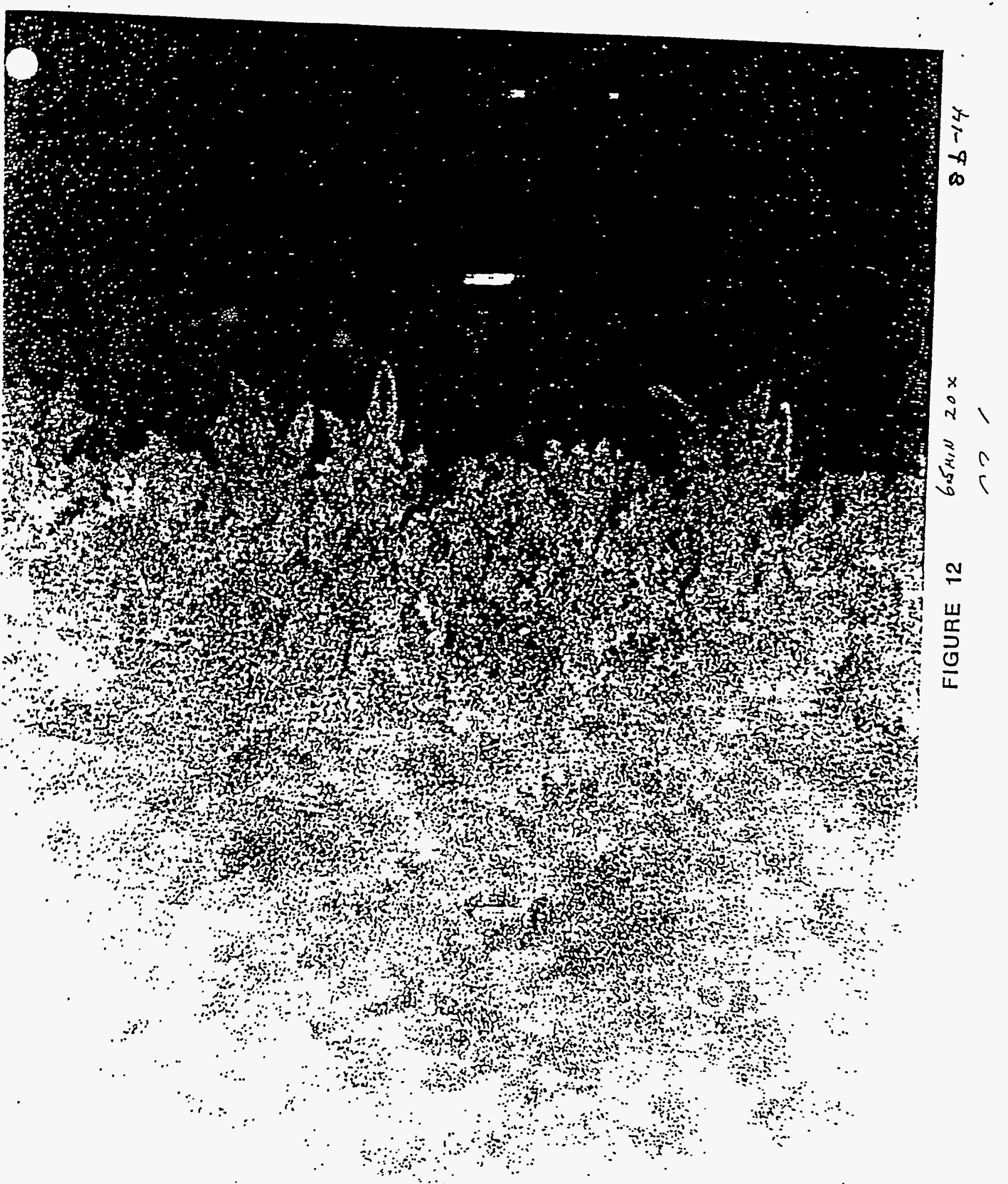


Frost experiments were performed in an 18-in glass belljar vacuum system, at dry vacuum near $10^{-5}$ torr. Water vapor was introduced at pressures 3-7 torr using only a mechanical pump for vacuum. The experimental apparatus included a vapor supply consisting of a mechanically stirred stainless steel bucket containing water, a microtelescope coupled to TV and $35 \mathrm{~mm}$ cameras, frost crush measuring devices, equipment to remove frost samples for average density measurements, vertical and horizontal frost growth measuring scales, and liquid nitrogen cooled aluminum or stainless tubes $(9.5 \mathrm{~mm})$ on which the frost was grown. Flat plates were attached to the substrate at times to ascertain growth on flat surfaces. Various plastics were mounted on the tubes during certain tests to ascertain growth characteristics and integrity. Water vapor and atmospheric constituents were measured and recorded by a residual gas analyzer. Temperatures of the vapor supply, substrate inlet and outlet, LN cooled shroud, and vapor mist were monitored with chromel-constantin thermocouples (typically 10 mils).

For more sensitive global temperature measurement, and to measure the radial temperature of the frost during the growth process, $0.7 \mathrm{mil}$ microthermocouples were utilized. In most cases these were mounted in an array, then placed parallel and to the edge of the frost growth to allow precooling of the array prior to contact with the frost whiskers. Typically the array consisted of four microthermocouples, each about 100 mils apart. Prior to use, all thermocouples were calibrated in-house to ice, $\mathrm{CO}_{2}$, and $\mathrm{LN}$ temperatures. These data were fitted to a fifth order polynomial. Pressure was measured by an in-vessel transducer.

The basic mode of operation was conceived from data that indicated dendritic type of frost growth can be achieved by deposition from the vapor phase. Dendritic crystals are desired because this appears to be the strongest form of low density frost as well as the only way to insure uniformly low density. A water bath is the most convenient way of supplying the vapor. A water bath temperature of $273 \mathrm{~K}$ corresponds to a saturated water vapor pressure of about 5 torr. In each experiment, basic measurements included the frost growth rate, vapor supply conditions and the global pressure. Generally, the operation of sensors was verified, then the vapor supply filled with pure water at about $276 \mathrm{~K}$. The belljar was then pumped to the desired pressure and valved off. Liquid nitrogen was then passed through the specimen substrate, and the frost growth monitored up to the desired thickness. Post growth experiments included average density, crush strength, frost cooldown, fragility and a measurement of the global water partial pressure.

Figure C3-7 shows a typical early structure which is dendritic. The picture was taken 6.5 minutes into the test.

Figure C3-8 ETEC fig 13.

The small limbs of the dendrites are $150 \mu \mathrm{m}$ in width. Later in the same run, at 43 and 90 minutes, a tube structure develops in the frost as shown in Figure C3-9.

Figure C3-9 ETEC fig 14. 


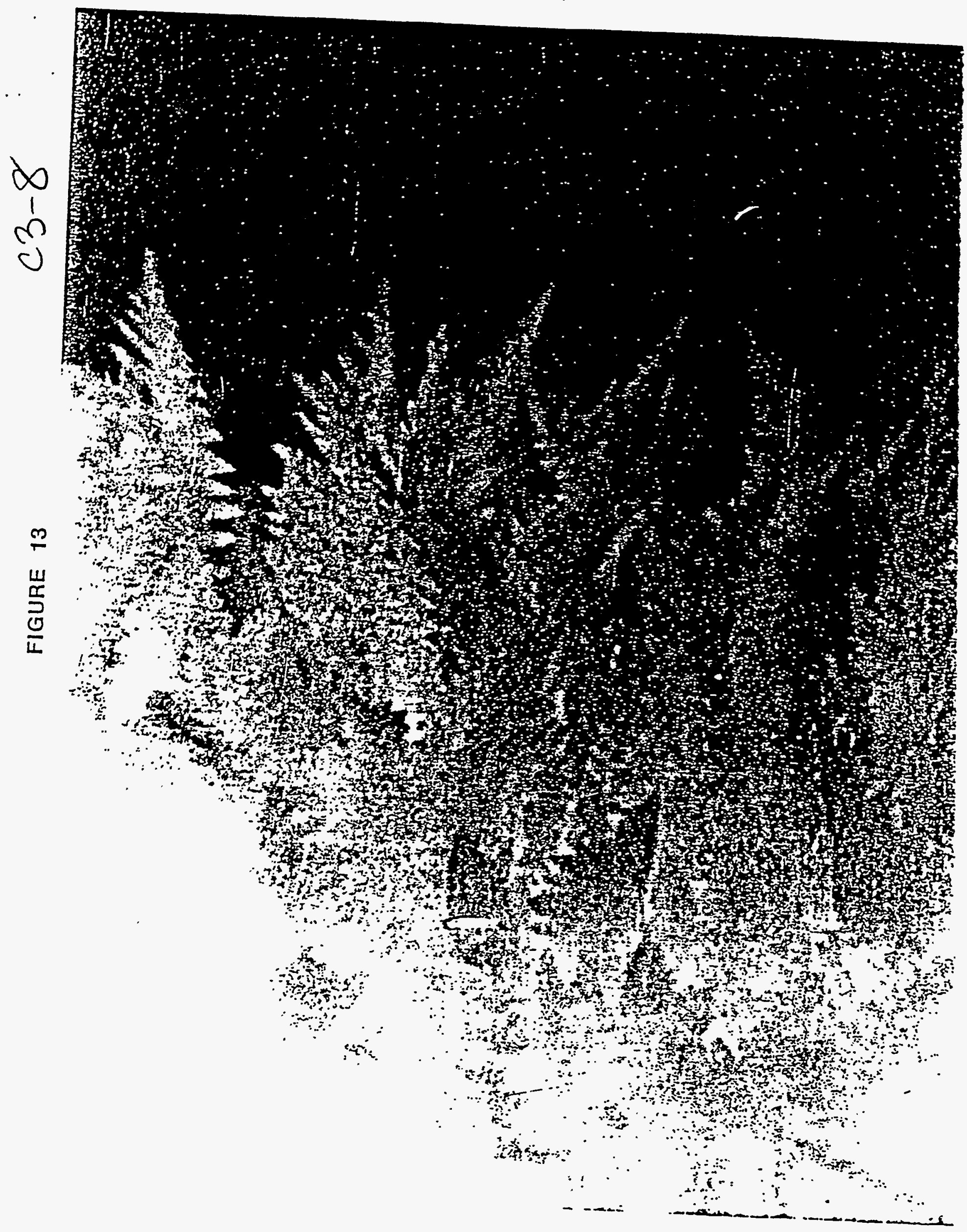


FIGURE 14

$(3-9$

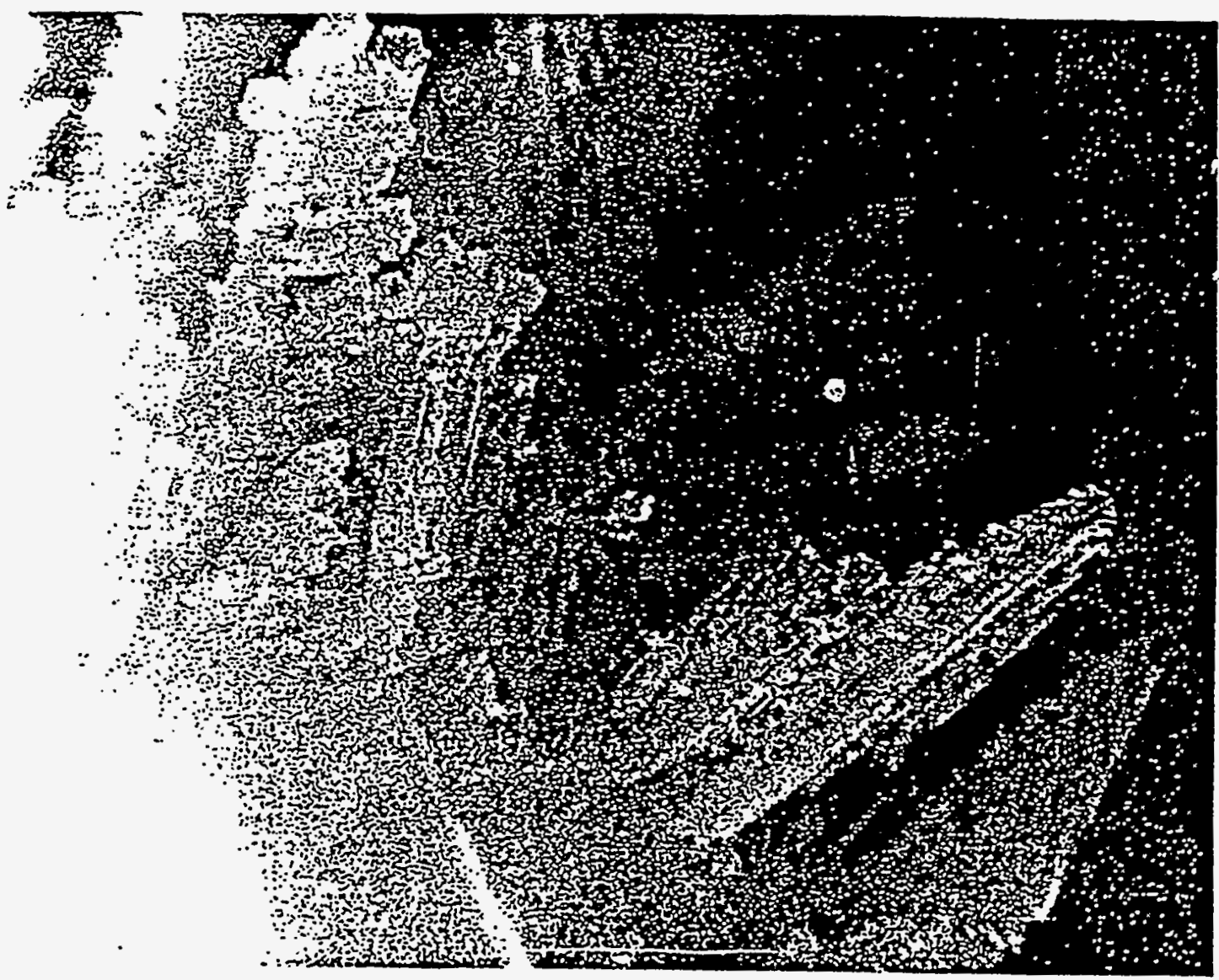

\section{FIGURE 15}

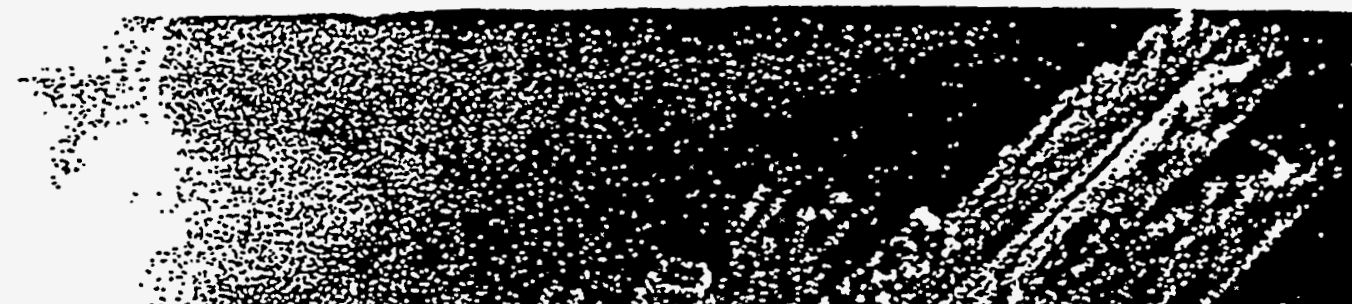

(n) S (n) and

(n)

Nof

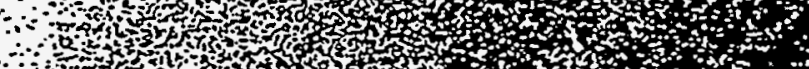

$\therefore \because y_{0}$

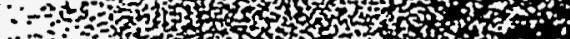

$\because 10$,

$\therefore$ or of

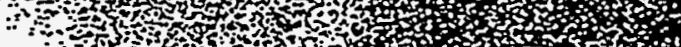

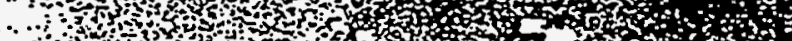

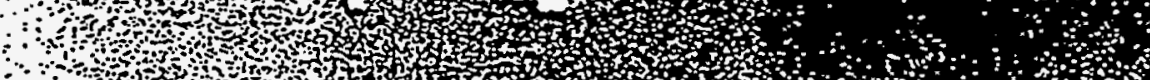

Ont

$\because-5=30$ H

-

$\therefore$,

$\because 30$ int 
The tubes here were hexagonal and long. In some cases they grew to $\sim 3 \mathrm{~mm}$ in length. That was presumed to be due to higher temperature growth at the outer surface of the frost layer.

In the initial experimental phase the ability to grow and maintain dendritic growth throughout the frost thickness was of major concern. In order to do this and stay in the dendritic region it was believed that the vapor supply had to be held at less than $1 \mathrm{C}$ during the growth process. To maintain this temperature range, salt was added to the vapor supply. Frost growth in general was not changed much, but analysis of the frost indicated that some of the salt had been carried to the substrate during the growth process. This line of experimentation was stopped since the neutron activation of salt in the LMF would increase the radiation dose rate.

Experiments using pure water were run at temperatures near $274 \mathrm{~K}$ and about 5 torr. It was shown that during the process when the pressure decreased to near the fluid vapor pressure, the fluid would bubble and splatter water in the system. This would cause high temperature vapor to migrate to the target and allow the frost structure to change from dendritic to hexagonal hollow tubes. The system pressure increased during this time also. Care should be taken to verify that this would not happen in the facility such that high strength dendritic frost growth is maintained in at least $60-70 \%$ of the frost growth. However, due to thermal resistance of the frost layer with growth and subsequent higher temperature of the frost surface, some tube growth should be expected.

\section{3) Growth rate results}

One of the basic measurements in every experiment was the radial frost growth rate. The experimental results indicate that the growth rates vary somewhat from experiment to experiment. Results from several experiments on an aluminum substrate are shown in Figure C3-10. 


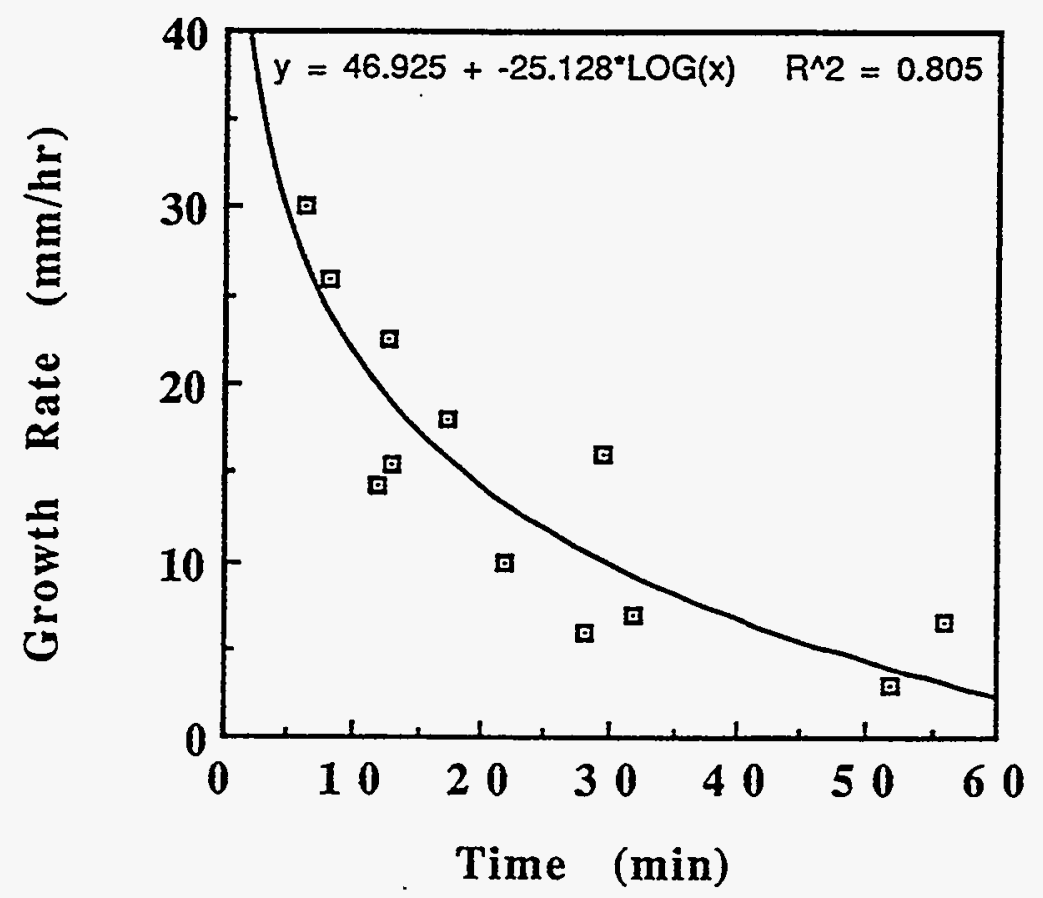

Figure C3-10 Frost growth rate during experiments.

The growth rate depends on the ratio of substrate surface area to the vapor supply surface area. The growth rates to obtain at least $10 \mathrm{~mm}$ of frost varied from $.07 \mathrm{~mm} / \mathrm{min}$ to $0.4 \mathrm{~mm} / \mathrm{min}$ for surface ratios of 5 to 0.5 respectively. In the typical growth experiment the frost growth rate would drop off by a factor of from 1 to 3 with time.

The declining growth rate was attributed in part to the increase in the number of nucleation sites as a function of time. It was also attributed to the increased temperature differential across the frost specimen. One precaution taken was that if the system was not leak tight, even though it was operated at about 5 torr, nitrogen gas would leak in and when pumped to maintain the pressure, the water vapor would be pumped preferentially and result in low growth rates.

The effect of non-metal substrates was investigated by wrapping the SS or AI tubes with polyethylene and teflon material. The plastics were held in place with epoxy or ties. There was almost no difference seen in the frost growth. Tests were later run to determine the fragility of the teflon frost specimen. By tapping the belljar ring that contained the $\mathrm{LN}$ inlet and outlet it was shown that the frost in the teflon region was only somewhat weaker than on the tube.

Typical frost grown on tubes was shown to be more or less homogeneous during the growth process. However, in the first part of the process, in all cases, the first deposition was a snow-like material consisting of platelets. After some deposition the snow-like base results in nucleation sites at which whiskers tend to form and cover the surface. 
There was some preliminary work done on frost growth on flat plates. After some experimentation with vertical, horizontal, round, square and grooved plates that were either welded or just strapped to the $L N$ cooled aluminum tube, frost was grown on flat plates. During the frost growth process (typically oriented vertically above the water vapor supply), it was shown that the platelet base layer would deposit quite homogeneously over the surface. However, the frost whisker growth on both sides of the plate was not homogeneous at all. Typically in vertical specimens the frost growth would start on the edge of the top half of the disk, at a growth rate about equal to that on an exposed tube. But, it took some time for the whiskers on the frost face to nucleate for general frost growth. During this time the platelet base still grew. Nucleation then started at the top edges and worked in on the top portion while taking longer to encompass the bottom and fill in. At some time the complete specimen would fill in and result in more or less homogeneous coverage. However, when viewing the specimen from the side it was obvious that the top frost was about 20-30\% thicker than the bottom portion of the $108 \mathrm{~mm}$ disk. These results suggest that more work is required to understand the mechanisms of frost growth, particularly with reference to the established vapor circulation patterns.

\section{4) Density results}

The density of the frost is an important factor since the ability to reduce shock wave damage represents one of the basic criterion for the frost concept. The average density of the frost was measured in several cases. During the program it was realized that the density measurement as a function of depth would be too complicated for this phase. Therefore our goal was only to develop the methodology to measure it.

There were two methods investigated to measure the incremental frost density: 1) cryogenic replication of ice crystals, and 2) an approach to section the frost, photograph it under magnification, then determine the density visually from the photograph. In both of these procedures, frost specimens have to be removed from the substrate.

To allow the removal of frost specimens, a LN cooled shroud was developed that could be manipulated from outside the belljar in post test conditions so as not to allow change in the frost characteristics. A knife operated from outside the belljar facilitated sectioning of the specimens. In the replication procedure, the specimen had to be removed from the belljar for mounting. In the photomicrograph procedure, the frost could be photographed through a special quartz window in the belljar collar by the microtelescope at typical conditions.

A variation of the photomicrograph approach is to section the frost on the substrate and take photo micrographs of the remaining frost cross section when it is still in place. In one of these experiments, the frost was sectioned and photographed through the microtelescope at 20x. The frost height was about $10 \mathrm{~mm}$ above the base frost, which has a thickness of 1 to $2 \mathrm{~mm}$. Frost growth occurs at nucleation sites on the base structure, then tends to branch out on the top like a bush to totally cover the substrate. The incremental density was not calculated from this 
photomicrograph, but the methodology was shown to be very adaptable for this type of application.

The average frost density was measured by removing a specimen down to the substrate either during or after the growth process, and weighing the resulting water as a function of the volume removed. For the tube measurements a bucket that cut the frost and caught the residue was developed. The knife was used to scrape the substrate while the belljar vacuum was maintained as not to allow further water condensation on the specimen. Immediately after the specimen was taken it was removed and weighed. In the case of flat plates it was scraped off the front face then processed in the same manner. These measurements resulted in average densities of $0.1 \pm 0.02 \mathrm{gm} / \mathrm{cm}^{3}$.

Additional experiments were run in which the platelet base frost average density was measured. These were done on aluminum plates by terminating the experiments early for density measurements. The resulting density for the platelet frost was $0.2 \pm 0.02 \mathrm{gm} / \mathrm{cm}^{3}$. The lower average density of the dendritic frost can be accounted for by the hollow tube structure. The flat aluminum plate frost specimen was grown to a typical $11 \mathrm{~mm}$. Then the vacuum was released with dry nitrogen, the belljar removed and the frost scraped. The substrate and the base frost around the scraped region could be clearly seen. The base platelet frost always seemed to have better integrity than the whisker material, even in the fragility tests. This was due probably to the platelet interbonding. This same phenomenon was seen many times in situ on tubes and plates. The generation of a small amount of platelet frost (20\%) seems the proper methodology for the LMF frost shielding concept because of the requirement that $100 \%$ of the first wall be covered. Even though the platelet frost does have a higher density, it helps to certify the above requirement and tends to lend to stability of the frost.

\section{5) Thermal conductivity}

The thermal conductivity was calculated for typical frost from the data presented in Fig. C3-11.

Figure C3-11 ETEC fig 26

Plotted is the radial temperature in degrees Kelvin vs. time in minutes during vapor supply quench with LN and frost cooldown. These data were recorded after the frost was grown to an average of $12 \mathrm{~mm}$ deep on a $9.5 \mathrm{~mm}$ OD aluminum tube. The 0.7 mil thermocouples were made with the $0.05 \mathrm{~mm}$ quartz sheath bent 90 degrees, resulting in different length thermocouples from 2.5 to $10 \mathrm{~mm}$. When mounted on the substrate tube this gave radial temperature measurement of the frost.

The temperature differential through $5.5 \mathrm{~mm}$ of frost was $50 \mathrm{~K}$. Assuming the density to be $0.09 \mathrm{gm} / \mathrm{cm}^{3}$, a growth rate of $4.2 \times 10^{-3} \mathrm{~mm} / \mathrm{s}$ and a heat flux of 2.8 $\mathrm{MJ} / \mathrm{kg}$, the average thermal conductivity of the frost was $0.12 \mathrm{~W} / \mathrm{m} \mathrm{K}$. This agrees with values found in standard tables to within 20\%. The data in Figure C3-11 were 


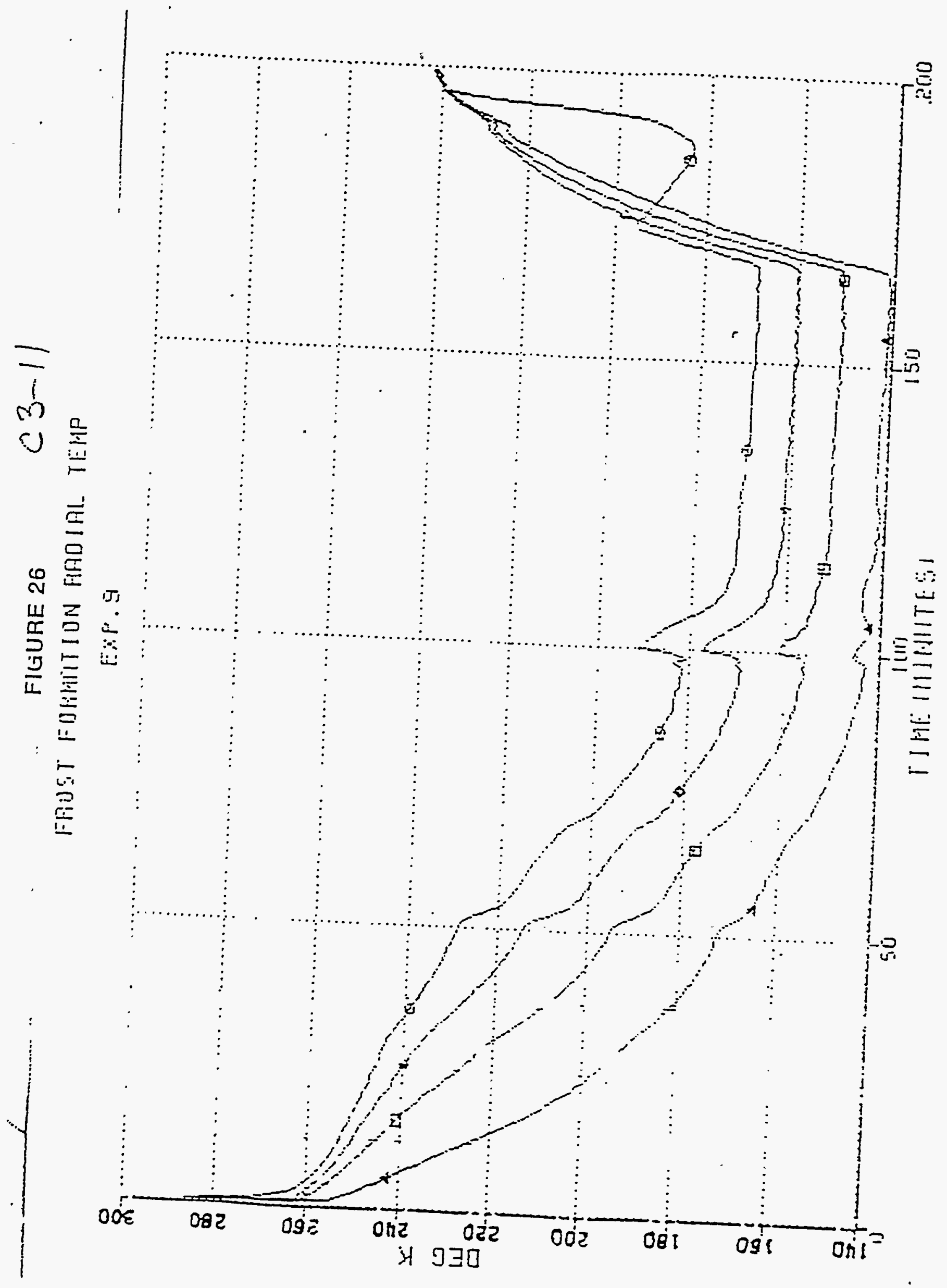


also used to calculate thermal conductivity as a function of temperature. The temperature difference between thermocouples at the time the frost growth was stopped ( 50 minutes into the test) was used to find an average temperature for each increment of frost deposited. The results are shown in Figure C3-12.

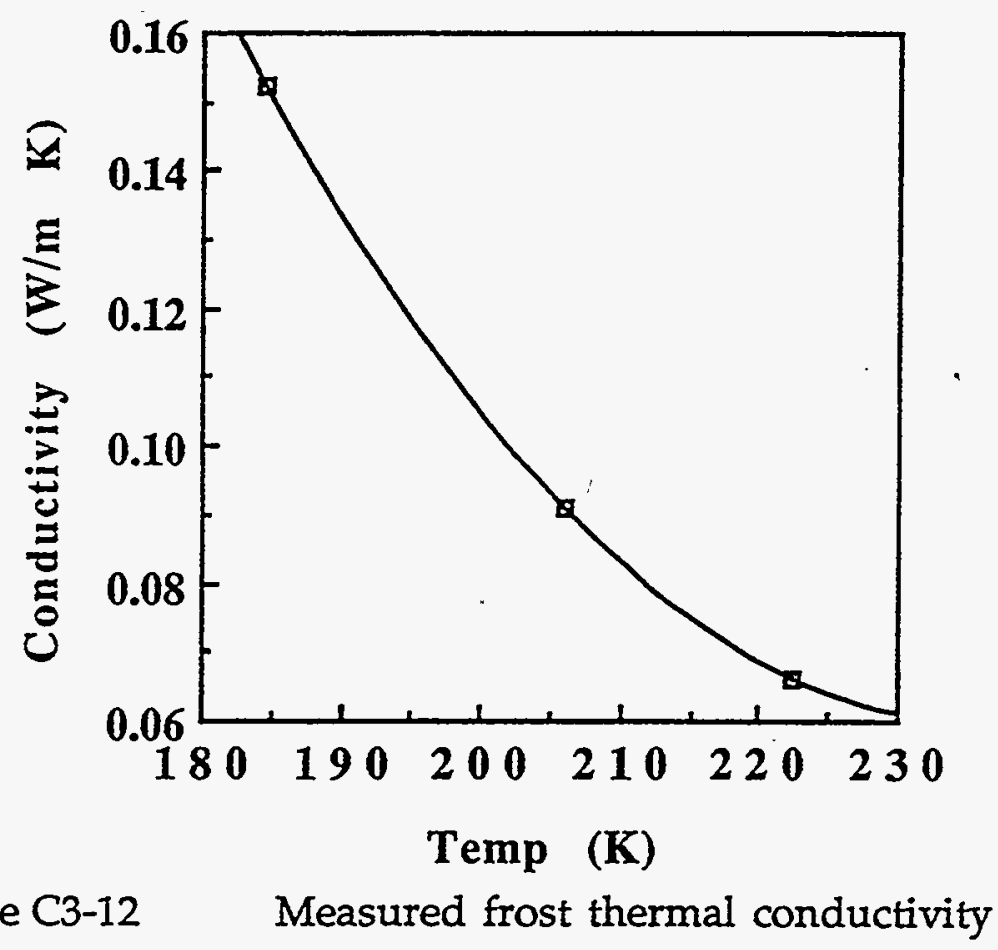

\section{6) Crush strength of frost}

Measurement of the load under which frost collapses were made to ascertain values for computer simulation of the frost shielding characteristics. Measurements were made with a calibrated semi-rigid strap and monitored by two TV cameras. One monitored the strap conforming to the frost cylinder while the other monitored the crushing of the frost between the strap and the substrate tube. Experiments showed the frost to be fully crushed at a load of $3.5 \mathrm{gm}$. The modulus of elasticity of this frost is not known but can be estimated from the modulus of elasticity of ice and the volume fraction of frost crystals. The estimated frost modulus is 1.0-1.5 $\times 10^{5} \mathrm{psi} / \mathrm{in} / \mathrm{in}$. Estimated values of the principal stress based on moduli in this range indicate that the $3.5 \mathrm{gm}$ load crushed the frost at a principle stress of roughly 1 bar.

\section{7) Frost integrity}

The maintenance of an integrated frost surface during typical operational activities prior to a shot is required for the LMF. During these activities the frost 
could be subject to vibration either during or after the growth stage. Design limits are required. The data shown in Figure C3-13 are frost temperatures during typical growth and cooldown where the vapor supply and the shroud were cooled with LN. The first 160 minutes represent the growth time. The remaining time was required to obtain a water partial pressure of less than $10^{-7}$ torr.

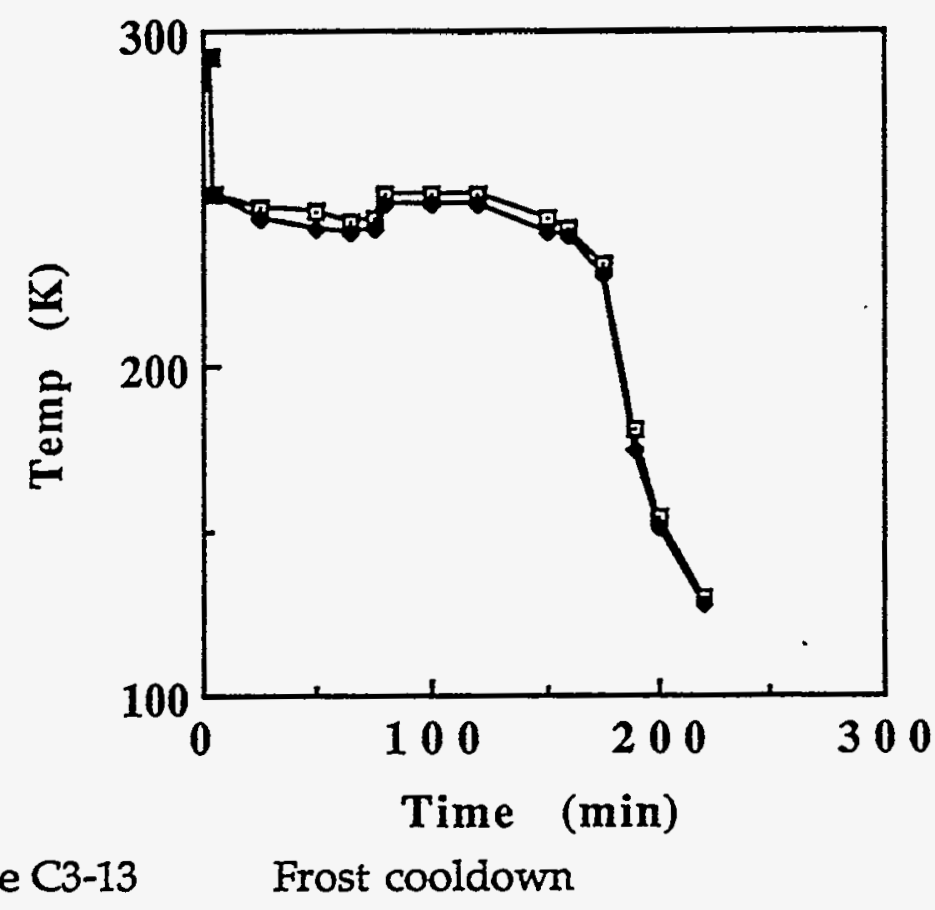

Since frost cracks can be repaired by the presence of sufficient water vapor, it was important to reduce the vapor pressure prior to performing the vibration experiments. The water partial pressure was measured on line by Residual Gas Analysis (RGA). Note that the frost vapor pressure falls rapidly with decreasing temperature 38 , as shown in Figure C3-14 below. 


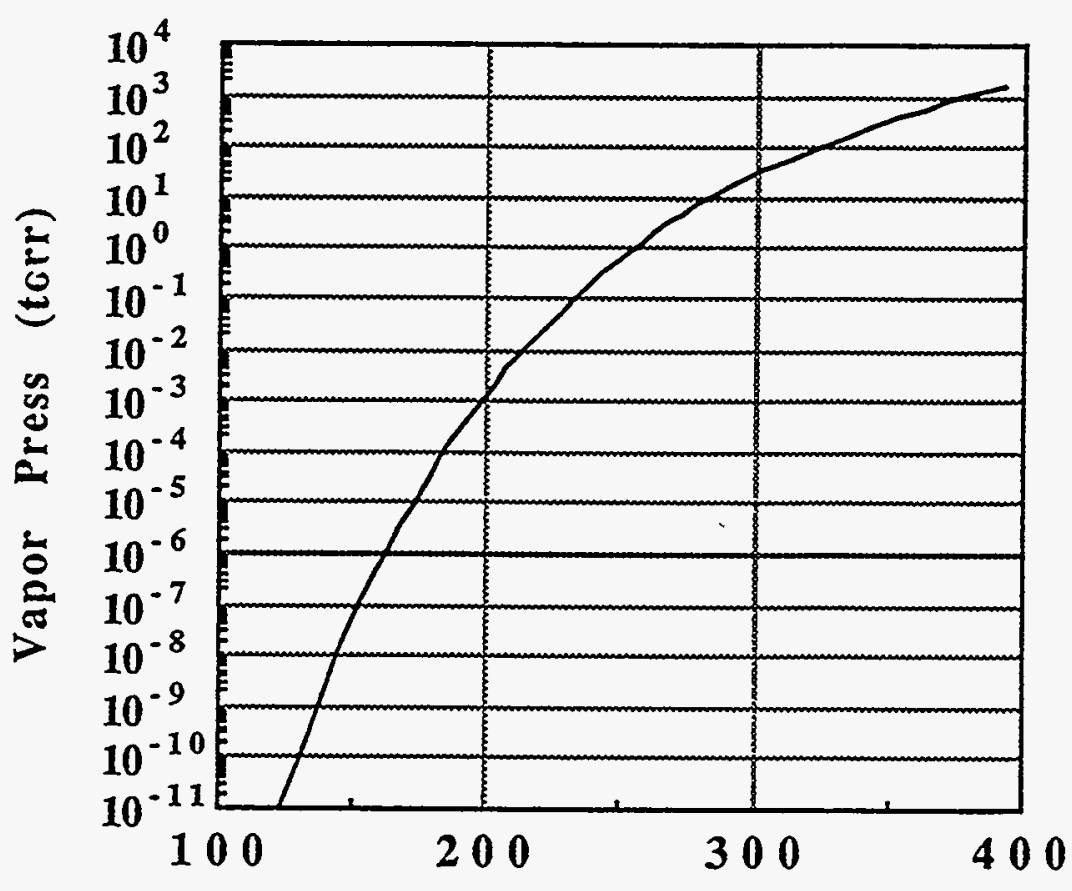

Temp (K)

Figure C3-14 Water vapor pressure as a function of temperature.

In these experiments the water vapor partial pressure after cooldown was measured to be $3 \times 10^{-8}$ torr. After the specimen had been at this low pressure for two hours, the fragility tests were run. A number of experiments were run with continuous belljar system vibration of about $0.1 \mathrm{~g}$ acceleration at $180 \mathrm{~Hz}$. Experiments were run in this mode during and after frost growth and resulted in no observable differences.

Hammer tests were performed after one hour of base vibration of the homogenized frost. The hammer tests ranged from $0.3 \mathrm{~g}$ to $25 \mathrm{~g}$ accelerations. The horizontal and vertical accelerations were both measured. The hammer blows were to the belljar collar which contained the inlet and outlet LN substrate tubes.

Cylinders of iron and lead weighing about $200 \mathrm{gm}$ each were used individually or together to hammer the collar in a pendulum fashion from sequentially further distances for higher acceleration levels. In all there were 25 separate hammer blows to the system. The maximum blows were at $25 \mathrm{~g}$ acceleration with a frequency of about $400 \mathrm{~Hz}$.

During the hammer blow experiments, which were performed on an aluminum tube $560 \mathrm{~mm}$ long, all of the top frost remained intact. On the bottom there was one region that lost about $10 \%$ of the whisker growth but not the platelet base frost during the entire set of hammer blows. However, there was no frost lost until blows of $10 \mathrm{~g}$ acceleration were imparted to the collar. It was shown during the set of experiments that the frost integrity was very good through $10 \mathrm{~g}$ specimen acceleration. The upper portion maintained integrity through $25 \mathrm{~g}$ acceleration tests. 
However, in the scaleup of the system the results may vary somewhat. Therefore; experiments will be required to verify integrity in a LMF scale application.

At the higher acceleration levels when the frost did fall from the bottom of the tube, the base platelet frost remained. One could experimentally develop methodology to overcome adhesion problems by raising the excess water vapor density for a short time, which would tend to cause freezing of the frost whiskers together. However, this appears not to be required at acceleration levels below $10 \mathrm{~g}$.

Having developed the technique for growing frost at predetermined and homogeneous low density, experiments were conducted to determine whether the resulting frost was viable as an $x$-ray absorbing and shock attenuating material. The next section describes the experiments and the results obtained.

\section{8) Frost response to simulated intense soft $x$-rays}

Verification of the frost protection concept was carried out experimentally using the intense proton beam at the Gamble-I facility 39,40 at the Naval Research Laboratory. Proton beams have been shown to be good simulators of soft xrays in the sense that they generate similar ablation and shock generation characteristics 41 . This follows from the fact that protons at energies below $1 \mathrm{MeV}$ have ranges in most materials which are similar to the mean free path of soft $x$-rays. Figure C3-15 below shows the dependence of proton range 42 on energy in carbon, aluminum, and low density water $\left(0.1 \mathrm{gm} / \mathrm{cm}^{3}\right)$. For purposes of comparison, the mean free path of $x$ rays 43 in the same material is shown. Note that the energy scales for protons and $x-$ rays are different in the plot. 


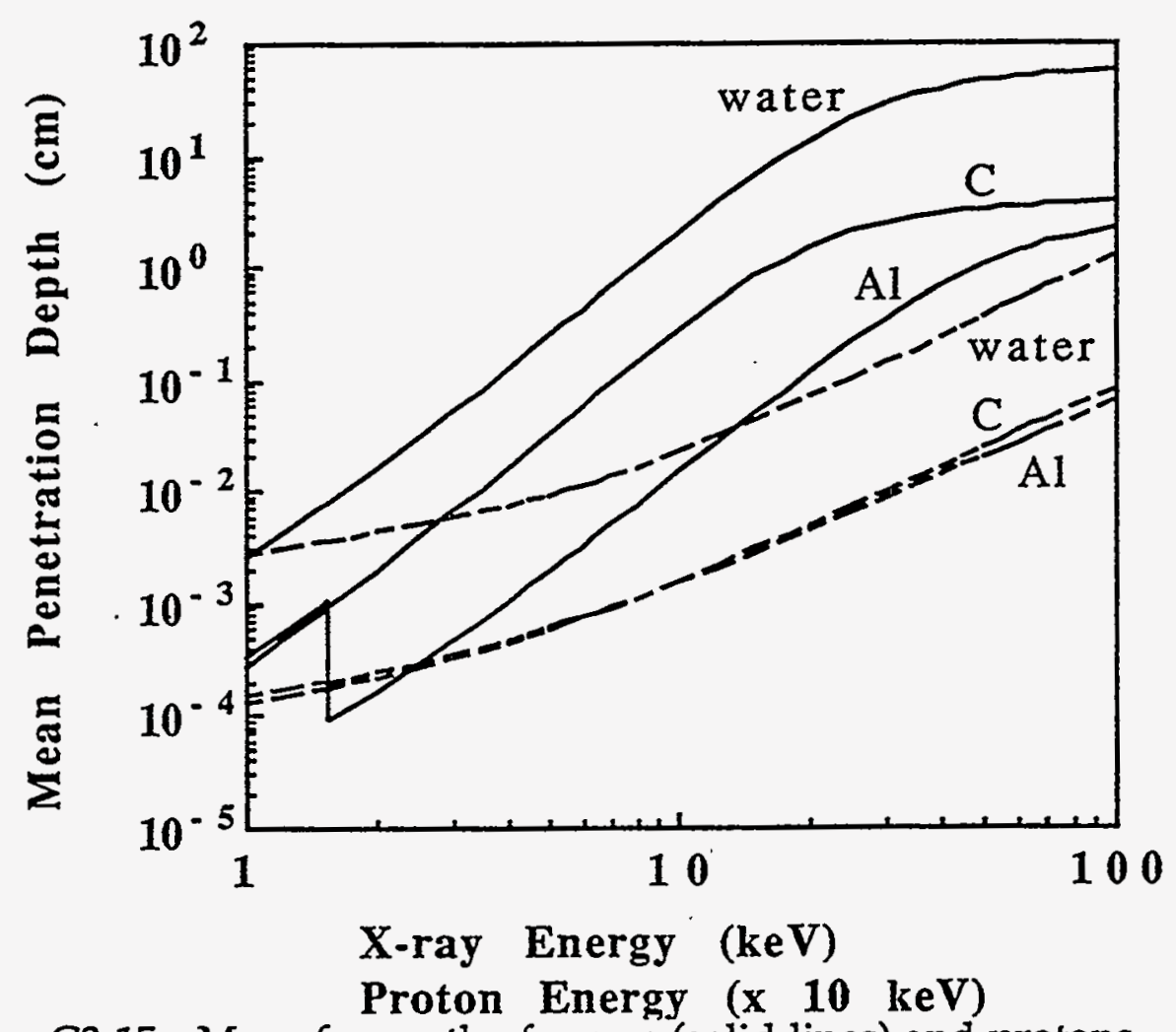

Figure C3-15 Mean free path of $x$-rays (solid lines) and protons (dashed lines).

Examination of the figure shows that protons at a few hundred $\mathrm{keV}$ have ranges similar to the mean free path of $x$-rays at energies of a few $\mathrm{keV}$. In the Gamble II experiments, 0.8-1.0 MeV protons in beams with energies of $12-15 \mathrm{~kJ}$ and durations $\sim 40 \mathrm{~ns}$ were delivered to samples as large as $100 \mathrm{~cm}^{2}$ or focused to provide intensities up to $500 \mathrm{~J} / \mathrm{cm}^{2}$. X-ray fluences in the LMF will be on the order of $100 \mathrm{~J} / \mathrm{cm}^{2}$ at a $\mathrm{R}=5 \mathrm{~m}$ wall for a full yield shot. The principal reason for choosing a proton beam over a plasma $x$-ray source for these simulations is the ability to direct, transport, and focus the beam onto samples of varying size. The ability to transport the beam and obtain a focus or point of convergence allows very high fluences and allows a large fraction of the energy in the source plasma to be delivered to the sample. While the usual Bragg distribution of energy deposition with depth would result in a rectangular rather than exponential deposition with distance, the angular divergence of the Gamble II beam fogether with its broad energy spectrum provide a depth profile which resembles that of $x$-rays ${ }^{44}$. The proton beam energy deposition density decreases approximately exponentially with distance into the target and the e-folding distance for a nominally $1 \mathrm{MeV}$ beam is only 1-2 $\mu \mathrm{m}$ in full density carbon, similar to that of a soft $x$-ray source whose mean energy is about $1 \mathrm{keV}$. Hanson ${ }^{41}$ has shown that proton beams at low energies such 
as these generate the same peak shock pressure in many materials as does a soft $x-$. ray puise of the same duration, fluence, and penetrating power.

In the proton beam experiments the frost was grown in-situ on typical flat substrates. Samples of frost on aluminum substrates were instrumented with piezoelectric devices for shock wave pressure measurements 45 . The flux, fluence and homogeneity were mapped prior to the frost experiments. Fluence measurement was calibrated during the beam mapping shots and was generated by ${ }^{13} \mathrm{C}(\mathrm{p}, \mathrm{n}){ }^{13} \mathrm{~N}$ reactions in graphite samples which yield a positron decay with 10 second half life. An array of carbon activation specimens were irradiated and counted immediately after a shot and related to the mean shot time for the beam fluence mapping and calibration.

Targets were constructed that would accommodate the pressure transducers to measure the shock wave generated through the frost and backing material. The design included the irradiation fixture that housed the targets, vapor supply, stirring motor and vacuum/cryogenic flanges that were required. The target assembly allowed for typical frost generation on the front side and transducer mounting on the back side as shown in Figures C3-16 and C3-17 below.

Figure C3-16 ETEC fig 84.

Figure C3-17 ETEC fig 85.

Aluminum as the first wall material had been preselected based on previous frost experimental results. It was the best candidate material with respect to frost growth rates, frost fragility and the requirement of low residual radiation.

The irradiation fixture consisted of six inch diameter beam piping sections, a flat 3-mm $\times 82 \mathrm{~mm}$ diameter aluminum disc as the target substrate (see Fig. C3-17 above) and viewing windows. The target disc was liquid nitrogen cooled through tubes fed into the vacuum chamber from rear cryogenic feedthroughs. The vapor supply to generate the frost was located at 90 degrees and just in front of the target. After the frost layer was grown on the disc, the vapor supply was lowered to liquid nitrogen temperature to reduce the fixture pressure while the frost target was maintained with $\mathrm{LN}$. The required target region pressure at the time of the shot was about 1 torr.

Since homogeneous frost had only been grown on a flat plate in a belljar system, a number of experiments were run in a typical NRL beam pipe to ascertain the proper location of the vapor supply and proper conditions. In all there were six checkout experiments to verify the adequacy of the fixture, then three irradiation experiments.

The irradiation experiments were run at two locations with respect to the proton anode, resulting in proton fluxes of 5 and $11.5 \mathrm{GW} / \mathrm{cm}^{2}$, corresponding to fluences of $150 \pm 50 \mathrm{~J} / \mathrm{cm}^{2}$ and $400 \pm 75 \mathrm{~J} / \mathrm{cm}^{2}$ respectively. The proton energy spread was from 0.7 to $1.0 \mathrm{MeV}$ and the pulse duration was stable at $\sim 38 \mathrm{~ns}$. Prior to the proton irradiations, frost was grown in-situ in the accelerator beam pipe. The frost in all shots varied from 10 to $12 \mathrm{~mm}$ thick. In the first shot the flux of $5 \mathrm{GW} / \mathrm{cm}^{2}$ 
FIGURE 84

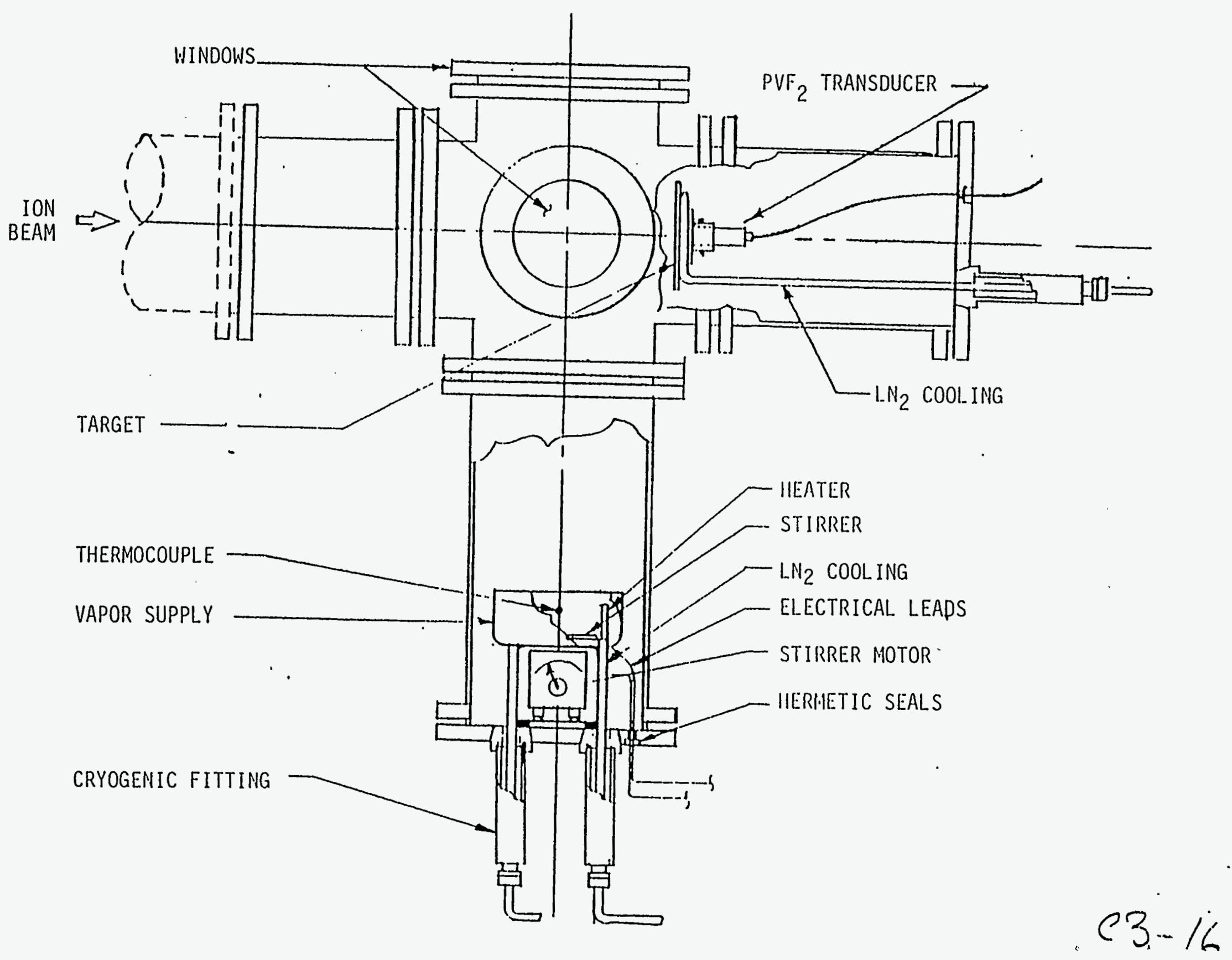




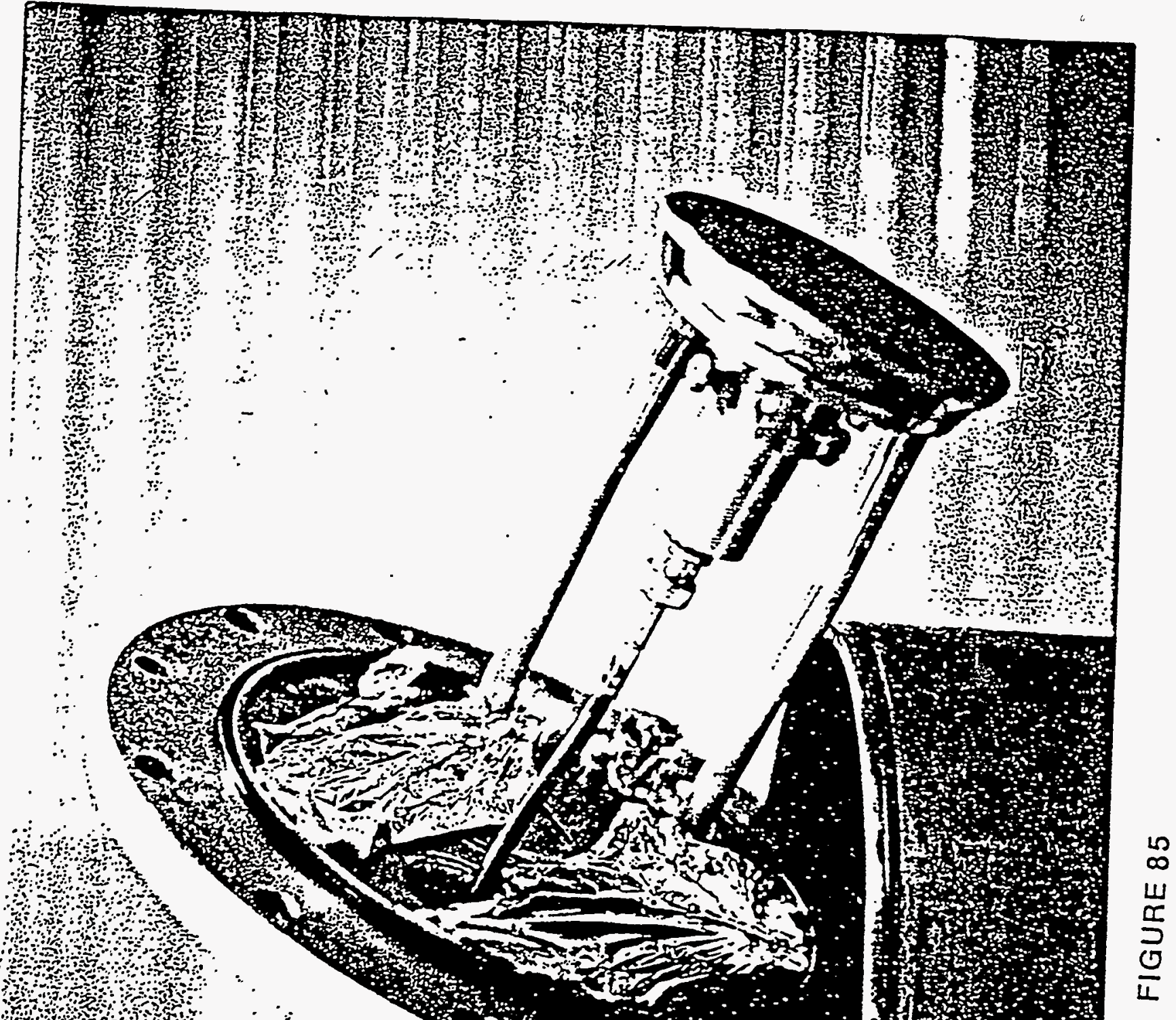


was at least a factor of two greater than the equivalent first wall loading in the LMF. The most intense portion of the beam (diameter $\sim 28 \mathrm{~mm}$ ) was about $10 \mathrm{~mm}$ off center but substantial intensities were observed over the full $150 \mathrm{~mm}$ diameter. The second and third shots were run at higher intensities. In those the target was centered with the beam intensity profile. It was postulated later that the transducer had probably failed prior to the first shot, and so shock measurements are not reported here. However, the frost integrity on the front face was maintained (see Figure C3-18 below.

\section{Figure C3-18 ETEC fig 87.}

and the flux/fluence was a factor of six higher than anticipated LMF first wall loading. The post shot picture shown in Fig. C3-18 of the frost target was taken after being removed from the irradiation facility. There was a large water hammer in the last energy shaping pulse, due to the closing of a water switch that occurred milliseconds after the proton pulse, which caused the outer frost layer down to about $3 \mathrm{~mm}$ to fall off. On the back of the target base where the transducers were mounted, much of the frost and all the base remained intact, i.e. no spalling occurred, which would have indicated a high pressure pulse.

The frost fluence measurements were backed up by carbon activation measurements taken during the irradiation. The activation specimens partially blocked the proton beam from the frost target, but no difference could be detected in the base frost after the irradiation.

The results of these experiments are important in the LMF conceptual design. They establish that it is possible to grow a protective layer of frost reproducibly at low density and to depths of up to $2 \mathrm{~cm}$. The strength of the deposited layer is sufficient to withstand the hostile conditions of a pulsed power experiment with its attendant shock forces and mechanical vibration. Vacuum requirements proved to be not critical even when experiments were delayed for hours after initial frost deposition, so that the useful lifetime of the protective layer has proven sufficient for an LMF application. Finally, and equally important, the deposited frost proved adequate to provide complete protection against erosion of the aluminum substrate up to simulated $x$-ray fluences much larger than those expected in the LMF. While it is important to note that the duration of the simulated $x$-ray pulse was long, $40 \mathrm{~ns}$, the peak flux was nearly half as large as the highest flux expected at the LMF wall. Even then, there was a residual frost and ice layer remaining on the aluminum substrate after the highest fluence used in these experiments, with the substrate undamaged. Consequently, we conclude that an aluminum first wall will not be damaged by moderate yield shots, and a controllable layer of frost may be deposited for full yield shots which provides protection against any wall damage with a substantial safety margin.

\section{Surrounding shielding and structures}

a) Cryogenic spheres-first wall and coolant containment 


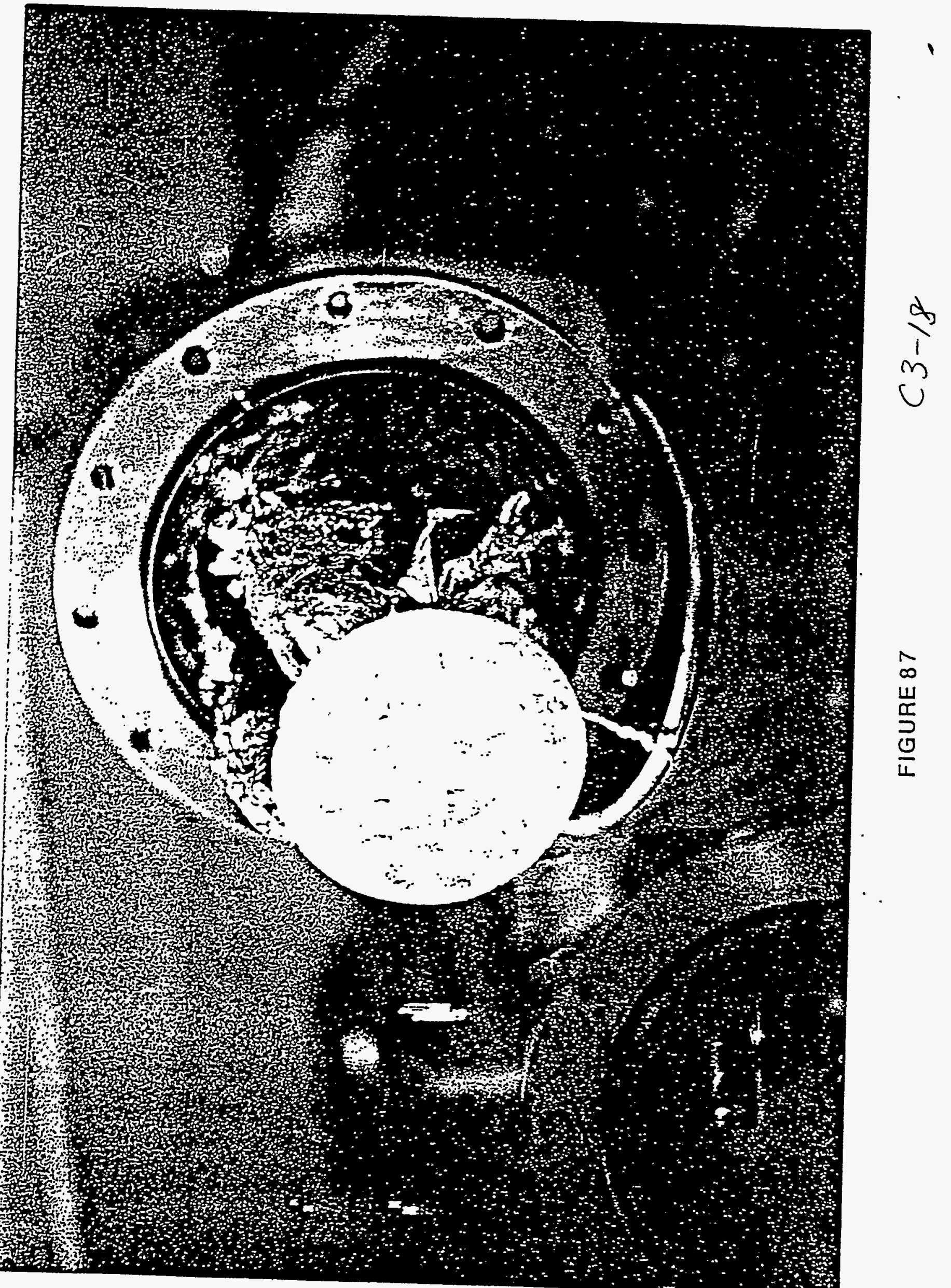


While the ability of a frost protected aluminum wall to withstand the shock forces generated by very bright $\mathrm{x}$-ray illumination has been established by a variety of analyses including computer and experimental simulations, the ultimate risk to the containment integrity may be due to late time residual pressure confined within the vacuum vessel as described earlier in section A4. In order to apply the methodology described earlier to the specific design proposed here the ASME Boiler and Pressure Vessel Code 84 was used to establish the dimensions of the aluminum spheres and the surrounding structures. The innermost wall, which is the vacuum wall, is loaded in compression by the 1.1 atmosphere coolant gas. The main criteria is buckling and, for $R=5 \mathrm{~m}$, a thickness of $3.18 \mathrm{~cm}$ is required for a maximum design tensile stress of $46.9 \mathrm{MPa}$, assuming the strength characteristics of 5083-0 aluminum. This is the lowest of the strengths available and is used in the analysis because there may be weak points at the welds. The second wall, which separates the coolant from the thermal vacuum, is loaded in tension and needs to be only $1.25 \mathrm{~cm}$ thick. These are the only two walls that must be cooled to cryogenic temperatures. Their total mass is $37,700 \mathrm{~kg}$.

The two concentric spheres are supported to the shield structure by a set of 18 flexing "V" links, as seen in Figures C4-1 and C4-2.

Figure C4-1 "V link suspension method to allow for shrinkage of spheres during cooldown while maintaining fixed center. (GA fig 2-9).

Figure C4-2 Detail of flexing suspension unit. (GA fig 2-10).

These links are of the type used to support superconducting magnets. They could be made of G-10 or G-11 dense fiberglass epoxy 85 or aluminum. The fiberglass will have lower thermal conductivity and be less prone to producing warm spots on the inner wall, but low ductility and possible problems due to cumulative neutron dose. The links can accommodate the $2.3 \mathrm{~cm}$ radial shrinkage of the spheres during cooldown to $100 \mathrm{~K}$. They are positioned near the equator so that spherical symmetry with respect to the optics is maintained.

Only the inner sphere moves due to the impulsive load from the vaporized frost. The outer sphere is fixed. The inner sphere is supported on the outer one by a large number of wave springs, as seen in Figure C4-3.

Figure C4-3 Method of supporting inner sphere so that it is free to move with respect to outer sphere. (GA fig 2-11).

The springs are tack-welded to the outer sphere. They are designed to support the weight of the inner sphere and keep it in position. They do not have to restrain the sphere to impulsive loads. As discussed below, that motion is absorbed into strain 


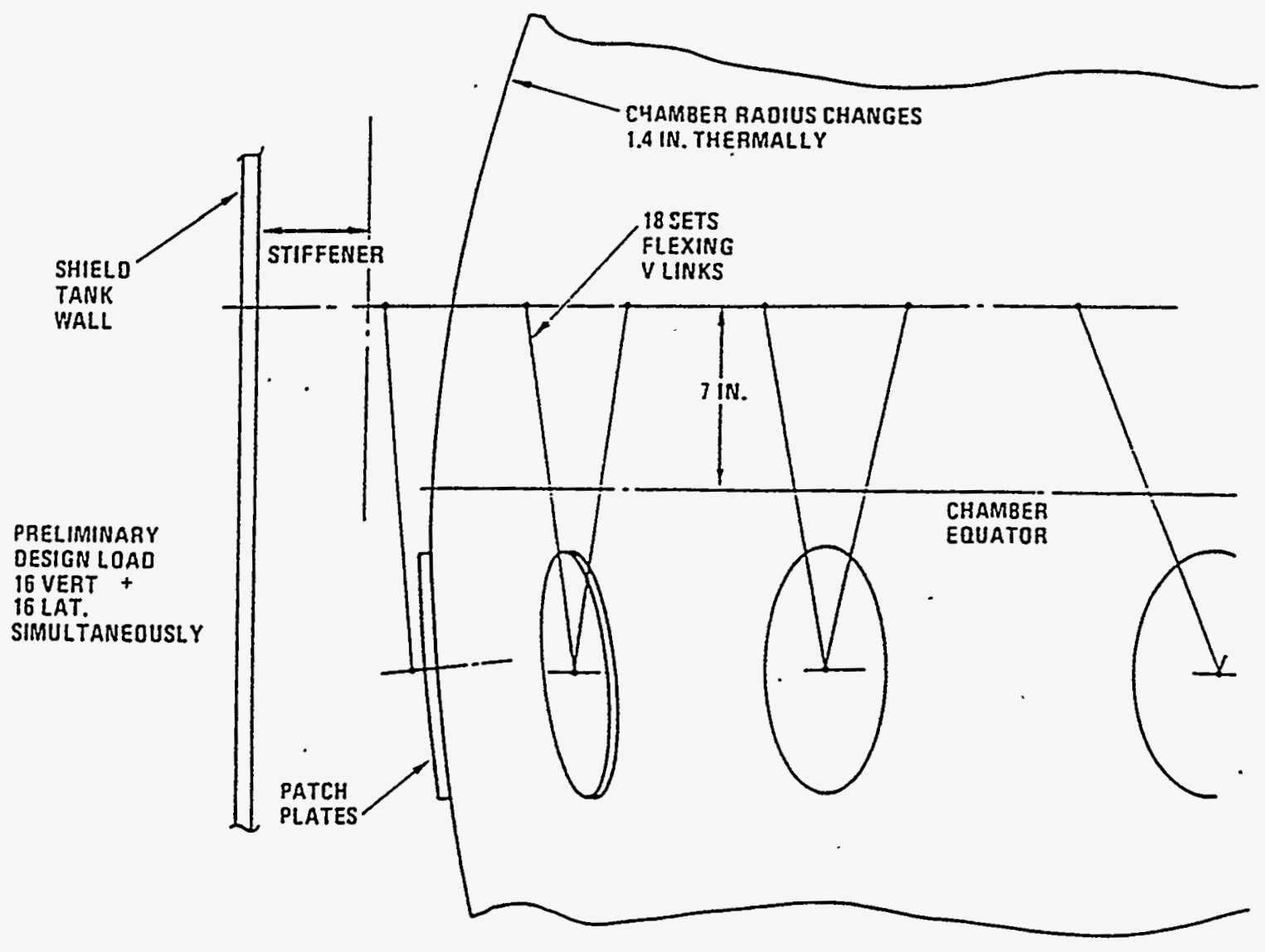

C4-1

Fig. 2-9. "V" link suspension method to allow for shrinkage of spheres during cooldown while maintaining fixed center. 


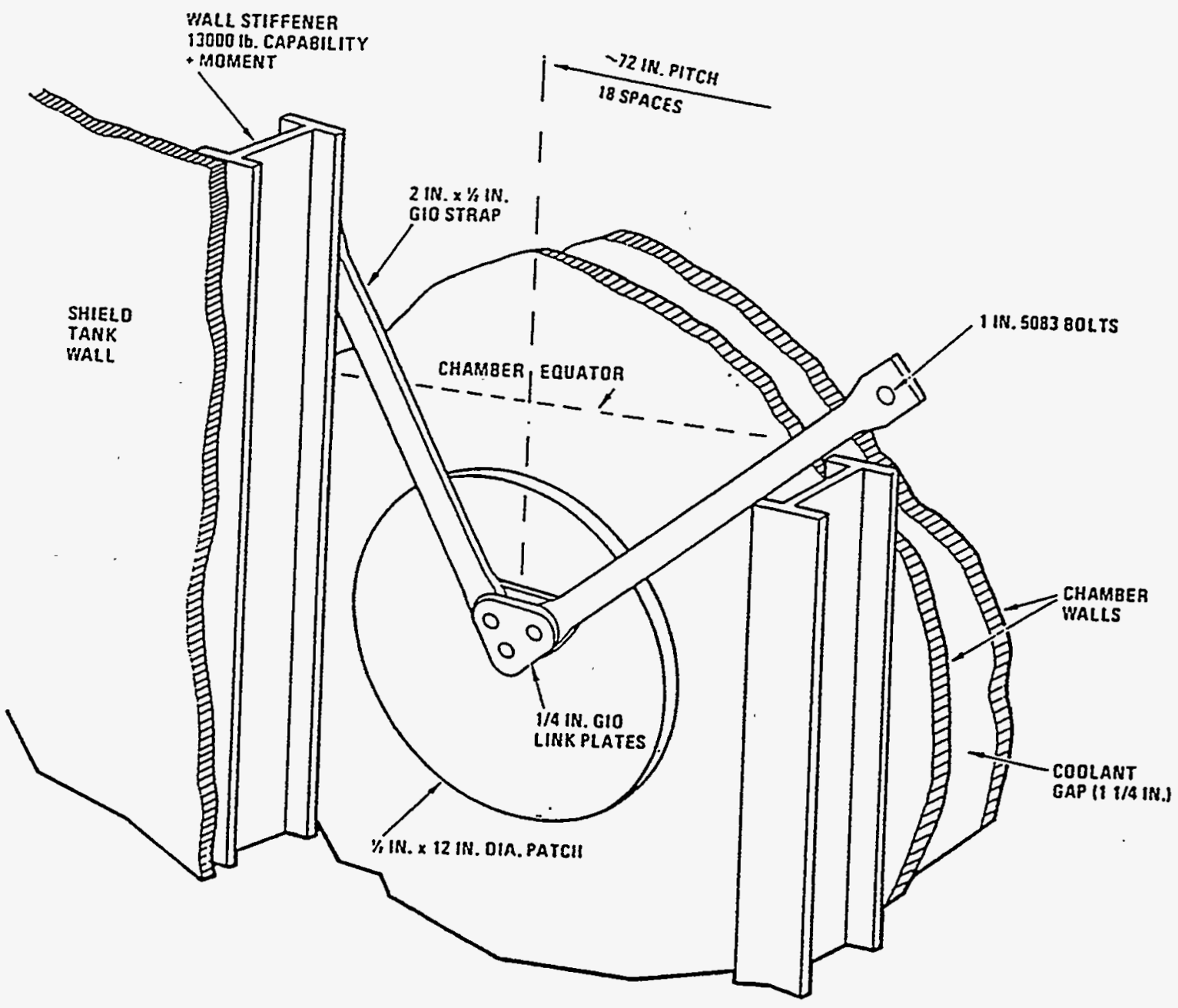

Fig-2-10. Detail of flexing suspension unit. $64-2$ 


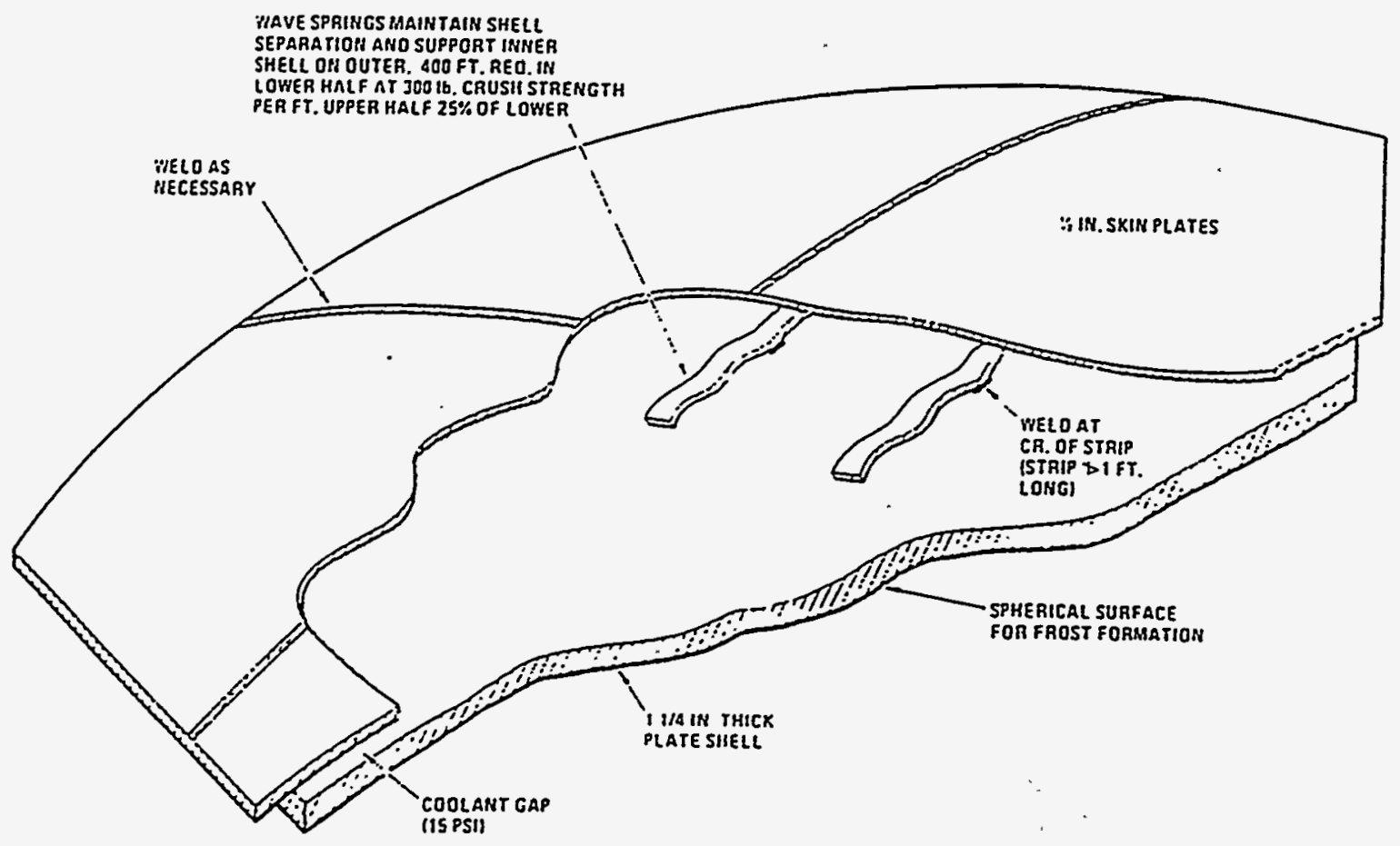

$C 4-3 \frac{\text { Fig. } 211}{\text { that it is free to move with respect to outer }}$ sphere. 
energy in the inner sphere itself. There are about 1500 wave springs altogether. Nominal load on each is about $25 \mathrm{~kg}$.

In addition to buckling, a major condition for sizing the thickness of the inner sphere is response to impulsive loads. The impulse from the frost in response to a $1400 \mathrm{MJ}$ shot at $R=5 \mathrm{~m}$ (see section A4) is $260 \mathrm{~kg}-\mathrm{m} / \mathrm{m}^{2}$ sec. With a wall area of $314 \mathrm{~m}^{2}$, the total impulse is $I=8.17 \times 10^{4} \mathrm{~kg}-\mathrm{m} / \mathrm{sec}$. The radial momentum and kinetic energy in the wall are:

$$
\text { mq̨u=I }
$$

and

$$
\mathrm{KE}=\frac{1}{2} \mathrm{~m}_{\mathrm{t}} \mathrm{u}^{2}
$$

where $\mathrm{m}_{\mathrm{t}}$ is the total mass of the inner sphere and $\mathrm{u}$ is the radial velocity. The kinetic energy is converted to elastic strain energy as the wall expands due to the impulse delivered:

$$
\mathrm{KE}=\mathrm{V}_{\mathrm{t}} \int \sigma \mathrm{d} \varepsilon=\frac{\sigma^{2} \mathrm{~V}_{\mathrm{t}}}{2 \mathrm{E}}
$$

where $\sigma$ and $\varepsilon$ are the stress and strain in the aluminum, respectively, once the shell has come to rest, $V_{t}$ is the total aluminum volume, and $E$ is the modulus of elasticity. Implicit in this model is that the strain is uniform. This treatment is accurate for thin shells and requires that acoustic waves in the shell have made several reflections in order to homogenize the stresses before appreciable motion or strain occurs. Both conditions are satisfied here. Since $m_{t}=\rho V_{t}$, where $\rho$ is the aluminum density, it can be shown that

$$
\sigma=\frac{I}{V_{t}} \sqrt{\frac{E}{\rho}}=\frac{I}{V_{t}} c
$$

where $c$ is the sound speed in the aluminum $(5100 \mathrm{~m} / \mathrm{sec})$. The total volume of the inner sphere is $9.97 \mathrm{~m}^{3}$. With $\mathrm{E}=6.9 \times 10^{10} \mathrm{~Pa}$, and $\rho=2700 \mathrm{~kg} / \mathrm{m}^{3}, \sigma=41.4 \mathrm{MPa}$. This is just below the ASME limit for hoop tension in 5083 aluminum. The wall moves radially outward $3 \mathrm{~mm}$ due to this motion.

An important, and unresolved, question is what happens to the inner sphere during rebound. It will move inward, acquiring the velocity $u$ at its original radius, and then go into compression. The question is whether or not this motion will induce buckling. A partial answer can be obtained by determining the external 
pressure that would be required to produce the compressive stress of $41.4 \mathrm{MPa}$ in the shell after it comes to rest. The hoop stress for a sphere is given by

$$
\sigma=\frac{\mathbf{P R}}{2 \mathbf{t}}
$$

where $t$ is the wall thickness. The equivalent pressure is then 5.2 atmospheres, about five times higher than the ASME limit. This may be acceptable because the inward momentum diminishes with inward motion. The ASME code is based on persistent external pressure. Nevertheless, this issue should be studied further in a full design study.

\section{b) Shield tank-primary neutron and $\psi$-ray shielding}

A primary neutron shield is required to reduce radiation level to which personnel are exposed directly and to reduce neutron activation of structures outside the containment. In this design a $3 \mathrm{~m}$ thickness of water is used for neutron attenuation. That results in a large mass of material which must be supported, and because the shield is a liquid, it imposes a hydrostatic load in one of the inner walls. This wall is then subject to buckling instability. The goal of the present analysis is to establish design parameters which assure that the dimensions and strength of materials used is adequate to assure the reliability of operation and adequate safety margins. The shield tank concept is shown schematically in Figure C4-4 below.

Figure C4-4 Shield tank concept. (GA fig 2-12).

The tank like structure is divided into three sections, each of which are vented to avoid excess hydrostatic loading. Pure water is used as the shield, and this occupies the annular space as well as the cylindrical space on the top and bottom. High purity aluminum-magnesium alloy are used for the inner structure and for the floors. Conventional 5083 aluminum is used for the outer wall and the top and bottom where direct exposure to the primary neutron flux does not occur. Calculations indicate that the sudden expansion of the water due to the near-instantaneous neutron heating will not cause pressure rise in vented shield tanks. The indicated temperature rise is several degrees $\mathrm{K}$.

\section{c) Secondary shielding}

The primary shielding is intended to reduce the neutron flux outside the containment to levels where neutron activation and personnel radiation exposure are acceptable. However, in a real design this shield, though sufficiently thick, is very imperfect in reducing the neutron levels outside the containment by the several decades required. There are 72 optics penetrations plus numerous holes for diagnostics. One of the problems is that neutrons are scattered by the primary 


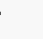




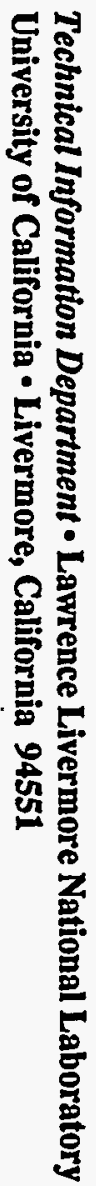

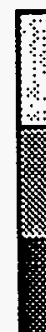

